\title{
HUBUNGAN PENGETAHUAN DENGAN PENCEGAHAN \\ OSTEOPOROSIS PADA WANITA PREMENOPAUSE DI WILAYAH KERJA PUSKESMAS MALAWEI KOTA SORONG
}

\author{
Novita Mansoben ${ }^{1}$ \\ Sekolah Tinggi Ilmu Kesehatan Papua \\ Email : novitamansoben@gmail.com \\ Maylar Gurning ${ }^{2}$ \\ Sekolah Tinggi Ilmu Kesehatan Papua \\ Email : maylargurning.ua@gmail.com \\ Veronika T. Soka ${ }^{3}$ \\ Sekolah Tinggi Ilmu Kesehatan Papua \\ Email : trisnasoka@gmail.com
}

\begin{abstract}
ABSTRAK
Pendahuluan : wanita premenopause mempunyai risiko untuk terkena osteoporosis dimana risikonya lebih tinggi yaitu 21,7 persen, dibandingkan dengan laki-laki yang hanya beresiko terkena osteoporosis sebanyak 14,8 persen. Tujuan penelitian : adalah mengetahui hubungan pengetahuan dengan pencegahan osteoporosis pada wanita premenopause di Wilayah Kerja Puskesmas Malawei Kota Sorong. Jenis penelitian ini menggunakan metode penelitian analitik kuantitatif dengan pendekatan cross sectional study. Penelitian dilaksanakan di Wilayah Kerja Puskesmas Malawei Kota Sorong pada tanggal 25 Februari -17 Maret 2020 dengan populasi sebanyak 264 respoden dan sampel sebanyak 159 responden diambil dari sebagian populasi dan menggunakan teknik accidental sampling. Instrumen penelitian menggunakan kuesioner dengan uji chi square. Hasil penelitian : ini menunjukkan bahwa pengetahuan dengan pencegahan osteoporosis diperoleh nilai $p$ value 0,001 artinya ada hubungan pengetahuan dengan pencegahan osteoporosis pada wanita premenopause di Wilayah Kerja Puskesmas Malawei Kota Sorong. Kesimpulan : bahwa ada hubungan pengetahuan dengan pencegahan osteoporosis di Wilayah Kerja Puskesmas Malawei Kota Sorong. Saran : bahwa Puskesmas sebagai wadah pelayanan kesehatan masyarakat dapat memberikan edukasi atau konseling tentang osteoporosis dan pencegahannya kepada wanita premenopause, sehingga lebih dini mengetahui dampak masalah dan pencegahan segera.
\end{abstract}

Kata kunci: Pencegahan osteoporosis, Pengetahuan, Wanita premenopause

\section{ABSTRACT}

Introduction : Premenopausal women are at risk for osteoporosis. Women have a higher risk of osteoporosis, namely 21.7 percent, compared with men who are only at risk of osteoporosis as much as 14,8 percent. The research objective : was to determine the relationship between knowledge and prevention of osteoporosis in premenopausal women in the Work Area of the Malawei Health Center, Sorong City. 
Novita Mansoben : Hubungan Pengetahuan dan Pencegahan Osteoporosis pada Wanita Premenopouse di Wilayah Kerja Puskesmas Malawei Kota Sorong

The research method: of this research is uses quantitative analytical research methods using a cross sectional study approach. The research was conducted in the working area of the Malawei Puskesmas, Sorong City on February 25 -17 March 2020. The population was 264 respondents and a sample of 159 respondents was taken from part of the population and used accidental sampling techniques. The research instrument used a questionnaire with the chi square test. The results : showed that knowledge with osteoporosis prevention obtained p value 0.001 was a relationship between knowledge and prevention of osteoporosis in premenopausal women in the working area of Puskesmas Malawei, Sorong City. The conclusion : is that there is a relationship between knowledge and prevention of osteoporosis in the Work Area of the Malawei Health Center in Sorong City. It is suggested : that the Puskesmas as a public health service forum can provide education or counseling about osteoporosis and its prevention to premenopausal women, so that they know the impact of the problem early and prevent it immediately.

Key words: Prevention of osteoporosis, Knowledge, Premenopausal women

\section{PENDAHULUAN}

Pertumbuhan dan perkembangan manusia pada prinsipnya terus berubah seiring bertambahnya usia. Peningkatan usia harapan hidup manusia tentunya akan memengarui perubahan baik secara fisik dan psikologis pada wanita maupun pria sampai terjadi proses menua (Irianto, 2015).

Pada umumnya setiap wanita akan mengalami perubahan dalam fase kehidupan. Proses ini berlangsung secara alamiah antar lain fase kelahiran, pra puberitas, puberitas, repoduksi, premenopause, menopause dan senium (Irianto, 2015). Saat wanita memasuki usia 40 tahun hingga 50 tahun maka akan mengalami gejala premenopause. Premenopause merupakan suatu keadaan dimana tidak terjadi menstruasi (Sulistyawati dan Atikah, 2010).

Salah satu perubahan fisik yang terjadi pada wanita premenopause yaitu penurunan hormon esterogen dan progesterone. Saat fungsi hormon esterogen dalam resorpsi tulang untuk menghambat proses kerapuhan tulang menjadi menurun maka kepadatan tulang pada wanita menjadi berkurang sehingga dapat terjadi osteoporosis (Irianto, 2015).

Menurut World Health Organization (WHO) 2014 dalam Pusdatin Kemkes, 2020 bahwa dalam penentuan tingkat keparahan osteoporosis menggunakan nilai $\mathrm{T}$ score saat melakukan pemeriksaan Bone Mineral Density (BMD), jika Tscore dibawah $<-2,5$ maka tergolong osteoporosis. Sedangkan jika T-score dibawah -1,0 maka digolongkan menjadi osteopenia.

Data International Osteoporosis Foundation (IOF) 2020 bahwa prevalensi kejadian osteoporosis pada wanita di Indonesia pada usia 50-70 tahun dan usia diatas 70 tahun sebesar 23 persen dan 53 persen. Sedangkan prevalensi wanita yang mengalami osteoporosis di Asia mengalami 
penurunan dari 35,2 persen menjadi 25,1 persen (Pusdatin Kemkes, 2020).

Menurut Departemen Kesehatan RI, 2014 bahwa angka kejadian osteoporosis pada wanita lebih tinggi yaitu 21,7 persen dibandingkan dengan pria mengalami osteoporosis yaitu 14,8 persen. Sehingga wanita yang memasuki pra lansia dan lansia termasuk dalam kelompok rentan dibandingkan wanita yang usianya lebih muda. Diperkirakan kepadatan tulang akan berkurang setiap tahunnya sebesar 0,5 hingga 1 persen pada wanita pasca menopause dan pria diatas usia 80 tahun (Dieny \& Fitranti, 2017).

Osteoporosis merupakan suatu keadaan dimana tulang menjadi rapuh atau mudah patah karena perubahan massa tulang mikroarsitektur jaringan tulang (Pusdatin Kemkes, 2020). Dampak dari osteoporosis dapat menyebabkan patah tulang hingga mengalami kematian akibat jatuh, perubahan postur tubuh, stres karena aktivitas menjadi terhalang, pengobatan yang mahal, mengalami keterbatasan sosial dan butuh bantuan orang lain (Pusdatin Kemkes, 2020).

Pencegahan osteoporosis dapat dilakukan sedini mungkin. Faktor yang dapat memengarui pencegahan osteoporosis antara lain mengonsumsi makanan yang kaya kandungan kalsium, melakukan aktivitas fi sik secara rutin, cukup mendapatkan paparan matahari sebagai vitamin $\mathrm{D}$, menghindari minuman yang beralkohol dan berkafein (Pusdatin Kemkes, 2020).

ISSN 2502-1524
Data Puskesmas Malawei Kota Sorong tahun 2019 bahwa jumlah lansia aktif sebanyak 1.679 dengan prevalensi wanita premenopause yang mengalami osteoporosis sekitar 80-85 persen. Hasil wawancara pada 10 orang wanita premenopause umur 45-50 tahun tentang pencegahan osteoporosis dimana 7 orang diantaranya tidak mengetahui.

\section{TUJUAN PENELITIAN}

Penelitian ini bertujuan untuk mengetahui hubungan pengetahuan dengan pencegahan osteoporosis pada wanita premenopause di Wilayah Kerja Puskesmas Malawei Kota Sorong.

\section{METODE PENELITIAN}

Penelitian ini merupakan analitik kuantitatif dengan pendekatan cross sectional study. Penelitian ini dilaksanakan di Wilayah Kerja Puskesmas Malawei Kota Sorong pada tanggal 25 Februari sampai dengan 17 Maret 2020. Populasi pada penelitian ini sebanyak 264 orang dilihat dari angka kunjungan ke Pos Lansia tiga bulan terakhir yaitu bulan Oktober, November dan Desember dengan jumlah sampel sebanyak 159 wanita. Pemilihan sampel menggunakan teknik accidental sampling yaitu sampel yang datang ke Pos Lansia dan memenuhi kriteria inklusi dan eksklusi yang ditetapkan oleh peneliti yaitu wanita premenopause usia 45 - 55 tahun, tinggal di Wilayah Kerja Puskesmas Malawei dan bersedia menjadi responden. Bahan yang digunakan dalam pengumpulan data berupa 
Novita Mansoben : Hubungan Pengetahuan dan Pencegahan Osteoporosis pada Wanita Premenopouse di Wilayah Kerja Puskesmas Malawei Kota Sorong

kuesioner pengetahuan dan pencegahan osteoporosis. Uji dalam penelitian ini yaitu uji chi square.

\section{HASIL PENELITIAN}

Tabel 1 Distribusi responden berdasarkan tingkat pendidikan di Wilayah Kerja Puskesmas Malawei Kota Sorong

\begin{tabular}{|c|c|c|c|}
\hline No & $\begin{array}{l}\text { Tingkat } \\
\text { Pendidikan }\end{array}$ & $\begin{array}{c}\text { Frekuensi } \\
(\mathrm{F})\end{array}$ & $\begin{array}{c}\text { Presentasi } \\
(\%)\end{array}$ \\
\hline 1 & SD & 72 & 45.3 \\
\hline 2 & SMP & 36 & 22.6 \\
\hline 3 & SMA & 34 & 21.4 \\
\hline 4 & $\begin{array}{l}\text { Perguruan } \\
\text { Tinggi }\end{array}$ & 14 & 8.8 \\
\hline 5 & $\begin{array}{l}\text { Tidak } \\
\text { Sekolah }\end{array}$ & 3 & 1.9 \\
\hline & Total & 159 & 100 \\
\hline
\end{tabular}

Sumber: Data primer 2020

Berdasarkan tabel 1 menunjukan bahwa distribusi responden berdasarkan tingkat pendidikan paling banyak adalah SD berjumlah 72 responden $(45,3 \%)$, dibandingkan dengan tidak sekolah sebanyak 3 responden $(1,9 \%)$.

Tabel 2 Distribusi responden berdasarkan tingkat pengetahuan di Wilayah Kerja Puskesmas Malawei Kota Sorong

\begin{tabular}{llcc}
\hline No. & $\begin{array}{l}\text { Tingkat } \\
\text { pengetahuan }\end{array}$ & $\begin{array}{c}\text { Frekuensi } \\
(\mathrm{F})\end{array}$ & $\begin{array}{c}\text { Present } \\
\text { ase }(\%)\end{array}$ \\
\hline 1 & Baik & 112 & 70.4 \\
2 & Kurang & 47 & 29.6 \\
\hline & Total & 159 & 100 \\
\hline
\end{tabular}

Sumber: Data primer 2020

Berdasarkan tabel 2 menunjukan bahwa distribusi responden bahwa tingkat pengetahuan baik lebih banyak yaitu 112 responden (70.4\%), dibandingkan dengan pengetahuan kurang baik berjumlah 47 responden $(29.6 \%)$.

Tabel 3 Distribusi responden berdasarkan pencegahan osteoporosi di Wilayah Kerja Puskesmas Malawei Kota Sorong Tahun 2020

\begin{tabular}{clcc}
\hline No. & $\begin{array}{l}\text { Pencegahan } \\
\text { Osteoporosis }\end{array}$ & $\begin{array}{c}\text { Frekuensi } \\
(\mathrm{F})\end{array}$ & $\begin{array}{c}\text { Presentase } \\
(\%)\end{array}$ \\
\hline 1 & Baik & 80 & 50.3 \\
2 & Kurang & 79 & 49.7 \\
\hline & Total & 159 & 100 \\
\hline
\end{tabular}

Sumber data primer 2020

Berdasarkan tabel 3 menunjukan bahwa distribusi responden menurut pencegahan osteoporosis pada kategori baik sebesar 80 responden $(50,3 \%)$ sama dengan pencegahan kurang sebanyak 79 responden $(49,7 \%)$.

Tabel 4 Hubungan pengetahuan dengan pencegahan osteoporosis di Wilayah Kerja Puskesmas Malawei Kota Sorong.

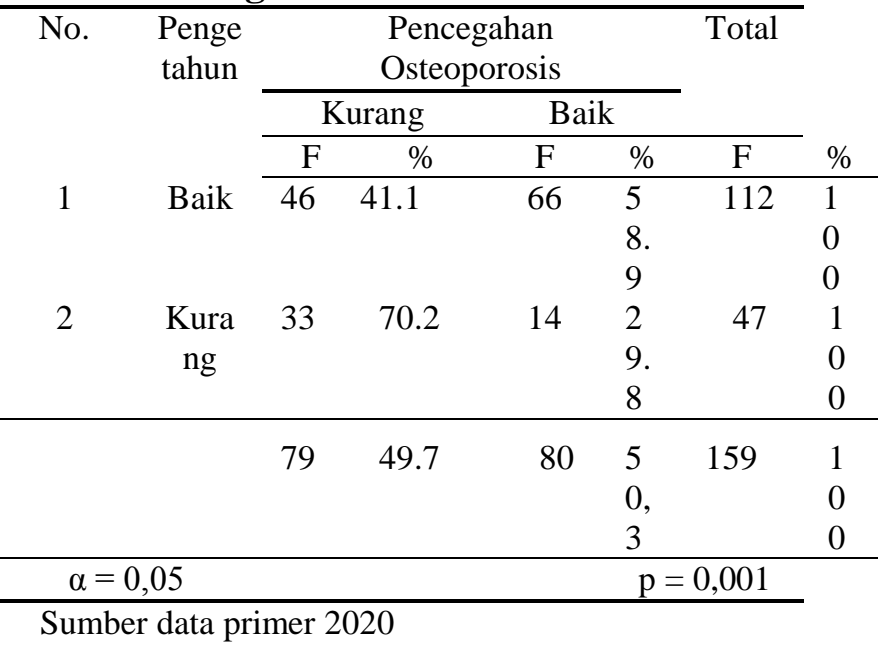

Berdasarkan tabel 4 menunjukan bahwa responden dengan pengetahuan baik dengan pencegahan osteoporosis baik sebanyak 66 responden $(58,9 \%)$ dan memiliki pengetahuan yang kurang dengan pencegahan osteoporosis sebanyak 46 responden $(41,1 \%)$. 
Sedangkan responden dengan pengetahuan kurang terhadap pencegahan kurang yaitu 33 responden $(70,2 \%)$ dan pengetahuan kurang terhadap pencegahan baik yaitu 14 responden $(29,8 \%)$. Berdasarkan hasil uji chi-square, diperoleh nilai $p=$ $0,001<\alpha=0,05$ dengan demikian $\mathrm{H} 0$ ditolak dan Ha diterima maka dari hasil tersebut ada hubungan pengetahuan terhadap pencegahan osteoporosis pada wanita premenopause di Wilayah Kerja Puskesmas Malawei Kota Sorong.

\section{PEMBAHASAN}

\section{Pengetahuan tentang osteoporosis}

Penelitian ini menunjukan bahwa wanita premenopause mempunyai pengetahuan baik lebih banyak dibandingkan dengan pengetahuan kurang tentang pencegahan osteoporosis. Pengetahuan merupakan hasil dari suatu objek yang diterima melalui penginderaan. Pengetahuan ini menjadi syarat penting terhadap perubahan perilaku (Pakpahan dkk, 2021).

Menurut Notoatmodjo (2012) menyebutkan bahwa pengetahuan memiliki beberapa unsur yaitu tahu, memahami, aplikasi, analisis dan sintetis. Artinya bila seseorang tahu dan memahami suatu objek maka dapat melakukan sesuatu yang diketahui. Social Cognitive theory yang dikembangkan oleh Bandura (1986) menjelaskan bahwa perilaku individu terbentuk karena adanya pengetahuan tentang risiko dan manfaat yang dirasakan (Pakpahan dkk, 2021).
Pengetahuan tentunya dipengarui oleh beberapa faktor antara lain umur, pendidikan, pekerjaan, minat pengalaman dan sumber informasi. Umur menunjukan tingkat kematangan seseorang dalam berpikir. Semakin tinggi umur maka proses pikirnya menjadi lebih baik dibandingkan dengan umur yang belum cukup (Notoatmodjo, 2012).

Tingkat pendidikan seseorang menunjukan tingkat pemahaman yang dimiliki. Semakin tinggi tingkat pendidikan maka semakin banyak yang diketahui sedangkan semakin rendah pendidikan seseorang maka proses pemahamannya juga semakin sedikit (Wawan dan Dewi, 2011 dalam Mifthahul, 2017).

Menurut Nurmala dkk (2018) bahwa pendidkan mempunyai pengaruh terhadap seseorang dalam menerima pesan yang didapatkan. Karena pendidikan memengarui proses pikir. Pada penelitian ini Pendidikan terakhir Wanita premenopause adalah Sekolah Dasar (SD) dibandingkan tingkat pendidikan yang lain.

Selain umur dan pendidikan, sumber informasi juga mempunyai peranan penting dalam peningkatan pengetahuan seseorang melalui metode dan media yang tepat. Media merupakan sarana komunikasi yang dipakai untuk menyampaikan pesan agar dapat meningkatkan pengetahuan sasaran.

Pengetahuan yang didapatkan merupakan hasil dari penerimaan pancaindra. Semakin banyak pancaindera yang digunakan maka semakin jelas atau mengerti terhadap 
Novita Mansoben : Hubungan Pengetahuan dan Pencegahan Osteoporosis pada Wanita Premenopouse di Wilayah Kerja Puskesmas Malawei Kota Sorong

pengetahuan yang didapatkan.

Menurut para ahli bahwa pancaindra mata lebih banyak menyalurkan informasi ke otak sebesar 75 persen hingga 85 persen, sedangkan pancaindra lainnya sebesar 13 persen hingga 25 persen (Siregar, 2020).

Metode yang dapat digunakan yaitu ceramah atau penyuluhan langsung ke masyarakat dengan menggunakan media komunikasi (Siregar, 2020). Menurut peneliti bahwa tingkat pengetahuan tentang pencegahan premenopause pada responden baik karena memperoleh informasi dari petugas kesehatan melalui penyuluhan kesehatan yang rutin dilakukan di Pos Lansia.

Hasil penelitian yang didapatkan dari responden bahwa pengetahuan terendah terdapat pada pertanyaan tentang risiko tulang keropos yang paling sering terjadi pada pria, olahraga yang tidak baik untuk tulang, rokok yang baik untuk kesehatan tulang, sinar matahari yang bermanfaat untuk tulang. Pemahaman yang rendah tentang osteoporosis tentunya akan berdampak terhadap pada perilaku pencegahan.

Menurut Kementrian Kesehatan RI (2015) bahwa pencegahan osteoporosis dapat dilakukan dengan meningkatkan pengetahuan masyarakat tentang risiko dan penyebab osteoporosis. Penelitian yang dilakukan oleh Melva dkk (2020) menunjukan bahwa sebagian besar responden memiliki pengetahuan sedang. Seseorang dengan pengetahuan yang baik akan memiliki kencendrungan melakukan perilaku yang baik juga.
Osteoporosis merupakan keadaan tulang menjadi mudah rapuh dan kondisi ini paling sering terjadi pada wanita yang memasuki usia premenopause hingga pascamenopause. Hal ini disebabkan kan karena perubahan fungsi hormone yang menurun seiring bertambahnya usia, dibandingkan pria (Pusdatin Kemkes, 2020).

Pencegahan osteoporosis dengan cara berolahraga yang teratur dan rutin sangat diperlukan karena dapat meningkatkan integritas tulang dan tonus otot sehingga terjadi keseimbangan tubuh. Olahraga yang dilakukan dapat menurunkan risiko jatih hingga 40 persen (Pusdatin Kemkes, 2020).

Kebiasaan merokok juga memengarui kepadatan tulang. Penelitian Nugraheni, 2021 melalui studi literature terhadap 8 artikel menemukan bahwa merokok dapat meningkatkan risiko osteoporosis pada lansia. Hasil penelitian Feriantika (2014) menemukan bahwa ada hubungan merokok dengan menopause dini pada perokok pasif dengan keeratan hubungan rendah dan sedang.

Pengetahuan tentang manfaat sinar matahari memberikan dampak positif terhadap pencegahan osteoporosis secara dini. Manfaat sinar mantahari tentunya memperkuat kepadatan tulang, sehingga kesimbangan kalsium didalam tulang tetap seimbang (Wirakusumah, 2007). 


\section{Pencegahan osteoporosis pada wanita premenopause}

Berdasarkan data diperoleh sebanyak 80 responden $(50,3 \%)$ memiliki pencegahan yang baik dibandingkan 79 responden $(49,7 \%)$ yang memiliki pencegahan kurang. Hasil penelitian ini menunjukan bahwa sebagian besar responden memiliki tingkat pencegahan yang baik tentang osteoporosis.

Hasil penelitian Wardhana dkk (2012) menyebutkan bahwa setiap 1 dari 3 wanita usia 50 tahun memiliki kecenderungan terkena osteoporosis ataupun terdapat kemungkinan yang terjadi sebanyak 67\%. Pengetahuan yang baik tentang pencegahan osteoporosis dapat mengurangi angka kejadian osteoporosis.

Osteoporosis dalam klasifikasi dibagi menjadi osteoporosis primer yang terjadi pada wanita yang pascamenopause pada tipe 1 yang terjadi sekitar 15 - 20 tahun setelah menopause dan osteoporosis sekunder yang disebabkan oleh penyakit atau pengobatan (Pusdatin Kemkes, 2020).

Pencegahan osteoporosis perlu dilakukan sebagai upaya peningkatan kesehatan individu, keluarga dan kelompok masyarakat melalui pemeliharaan kesehatan dan pendidikan kesehatan sesuai kebutuhan (Irianto, 2015).

Pemeliharaan kesehatan yang dapat dilakukan yaitu mengonsumsi makan kaya kandungan kalsium, melakukan aktivitas fisik secara rutin, mendapatkan haid teratur, berjemur dibawah sinar matahari pagi serta ISSN 2502-1524 menghindari minuman beralkohol, kafein dan rokok (Pusdatin Kemkes, 2020).

Hasil penelitian ini menunjukan upaya pencegahan yang jarang dilakukan adalah tergabung dalam klub olahraga, menghindari alkohol dan asap rokok, menghindari minuman kopi dan tidak melakukan konsultasi ke dokter jika nyeri pinggang. Sedangkan upaya yang sering dilakukan responden yaitu mengonsumsi susu yang mempunyai kalsium tinggi, melakukan aktivitas yang langsung terpapar dengan sinar matahari, serta membatasi jumlah garam yang dikonsumsi.

Terpapar asap rokok tentunya memberikan dampak bagi kesehatan. Dimana risiko osteoporosis lebih besar. Studi mengemukakan bahwa wanita perokok mempunyai kadar esterogen yang lebih rendah dan lebih cepat mengalami menopause dibandingkan dengan wanita bukan perokok. Karena didalam rokok terdapat kandungan nikotin yang menghambat penyerapan dan pengunaan kalsium. Selain itu, dengan mengonsumsi alkohol yang berlebihan tentunya akan memberikan luka pada dinding lambung sehingga dapat terjadi perdarahan sehingga tubuh kehilangan Kalsium (Utami, 2015). Oleh sebab itu, upaya pencegahan yang dilakukan adalah tidak mengonsumsi alkohol dan rokok.

Melakukan konsultasi dengan tenaga kesehatan lainnya merupakan hal yang penting untuk mengidentifikasi gejala yang ditimbulkan dari osteoporosis. Hal ini dikarenakan osteoporosis disebut sebagai silent disease karena gejala 
Novita Mansoben : Hubungan Pengetahuan dan Pencegahan Osteoporosis pada Wanita Premenopouse di Wilayah Kerja Puskesmas Malawei Kota Sorong

yang dirasakan merupakan dampak dari fraktur. Gejala yang sering dirasakan yaitu nyeri pada area punggung dan pinggang dan berlangsung dalam kurun waktu yang lama (Pusdatin Kemkes, 2020).

Menurut asumsi peneliti, bahwa tingkat pencegahan dalam kategori baik karena mempunyai pengetahuan yang baik tentang osteoporosis.

\section{Hubungan pengetahuan dengan pencegahan osteoporosis pada wanita premenopause.}

Hasil uji statistic chi-square menujukan bahwa ada hubungan pengetahuan dengan pencegahan osteoporosis pada wanita premenopause di Wilayah Kerja Puskesmas Malawei Kota Sorong.

Pengetahuan merupakan bagian penting dari perubahan perilaku. Perubahan perilaku yang terjadi dapat berupa covert behavior dimana perilakunya masih tertutup karena belum jelas dengan apa yang diamati, dan overt behavior yaitu perilakunya terbuka dari apa yang dipelajari sehingga menimbulkan tindakan (Pakpahan, 2021).

Salah satu kategori perubahan perilaku kesehatan menurut Glans, dkk (2008) yaitu preventif health behavior.

Dimana pencegahan ini bertujuan untuk menjaga agar dirinya tetap sehat. Untuk meningkatkan perilaku kesehatan maka diperlukan pengetahuan yang baik untuk mengetahui risiko dan manfaat (Pakpahan dkk, 2021).

Asumsi peneliti pada hasil penelitian ini bahwa tingginya ISSN 2502-1524 pengetahuan wanita yang memasuki fase premenopause memberikan dampak pada tindakan pencegahan untuk mengurangi risiko dari osteoporosis. Hasil Pada penelitian ini menunjukan bahwa mayoritas responden dengan pengetahuan baik mempunyai kemampuan untuk melakukan pencegahan osteoporosis yang tinggi sebesar 58,9\%, dibandingkan dengan responden yang mempunyai pengetahuan kurang terhadap perilaku pencegahan osteoporosis yaitu $29,8 \%$.

Meskipun mayoritas wanita usia premenopause mempunyai upaya pencegahan osteoporosis yang baik, namun sekitar $41 \%$ mempunyai pencegahan yang kurang dengan tingkat pengetahuan yang baik. Hal ini dapat terjadi karena pencegahan dalam melakukan olahraga, berjemur dibawah panas matahari pagi dan masih terpapar asap jarang dilakukan.

Hasil penelitian ini sejalan dengan penelitian Miftahul (2017) bahwa ada hubungan antara pengetahuan wanita usia premenopause dengan perilaku pencegahan osteoporosis. Selain itu, penelitian Rizkia, 2012 menemukan bahwa ada hubungan yang bermakna antara pengetahuan dengan perilaku pencegahan osteoporosis dengan arah hubungannya positif. Namun Penelitian Wildawati dkk, 2020 menunjukan hasil yang tidak sejalan antara pengetahuan dengan pencegahan osteoporosis, karena wanita dengan pendidikan tinggi tidak menjamin untuk mau mengaplikasikan atau melakukan pengetahuan yang dimiliki. 
SIMPULAN DAN SARAN

\section{SIMPULAN}

Ada hubungan yang bermakna antara hubungan pengetahuan dengan pencegahan osteoporosis pada wanita premenopause di Wilayah Kerja Puskesmas Malawei Kota Sorong.

\section{SARAN}

Diharapkan pihak puskesmas dapat memberikan edukasi atau konseling kepada wanita premenopause tentang osteoporosis dan upaya pencegahan yang dapat dilakukan sehingga angka kejadian osteoporosis dapat diturunkan.

\section{DAFTAR PUSTAKA}

Arikunto, S. 2010. Prosedur Penelitian Pendekatan Praktik. Jakarta : Rineka Cipta.

Depkes, 2014. Kecenderungan Osteoporosis di Indonesia 6 Kali Lebih Tinggi Dibanding Negeri Belanda. Jakarta: Litbangkes.

Dieny F.F \& Fitranti Y.D. 2017. Faktor risiko osteoporosis pada wanita usia 40-80 tahun: status menopause dan obesitas. Jurnal Gizi Klinik Indonesia Vol. 14 No. 2 (45-55) ISSN 2502-4140. Diakses melalui https://core.ac.uk/reader/2962662 $\underline{70}$.

Feriantika, L. 2014 Faktor-Faktor Yang Mempengarui Kejadian Menopause Dini Pada Wanita.

ISSN 2502-1524
Diakses melalui http://repository.unjaya.ac.id/837/

International Osteoporosis Foundation. 2020. World Osteoporosis Day. Diakses melaui https://www.osteoporosis.foundat ion/

Irianto. K. 2015. Kesehatan Reproduksi (Reproductive Health) Teori \& Praktikum. Bandung: Penerbit Alfabeta

Karolina, MS. 2016. Hubungan Pengetahuan dan Pencegahan Osteoporosis yang Dilakukan Lansia di Kecamatan Medan Selayang. Medan, FK-USU, Skripsi. Diakses melalui http://repository.usu.ac.id/handle/ $\underline{123456789 / 14298}$

Kementerian Kesehatan RI. 2015. Pusat data dan informasi data dari kondisi penyakit osteoporosis di Indonesia. Jakarta: Departemen Kesehatan.

Melva M, Dosmaida N, dan Pretty S, 2020. Hubungan Pengetahuan Dengan Upaya Pencegahan Dini Osteoporosis Wanita Usia 45-60 Tahun. Jurnal Keperawatan Priority. Vol 3, No 2. Diakses melalui

http://jurnal.unprimdn.ac.id/index .php/jukep/article/view/969

Miftahul K. 2017. Hubungan Pengetahuan Wanita Usia Tentang Osteoporosis Premenopause dengan Perilaku Pencegahan Osteoporosis. Skripsi. Stikes Insan Cendekia Medika Jombang. Diakses Page | 112 
Novita Mansoben : Hubungan Pengetahuan dan Pencegahan Osteoporosis pada Wanita Premenopouse di Wilayah Kerja Puskesmas Malawei Kota Sorong

melalui http://repo.stikesicmejbg.ac.id/221/1/Skripsi\%20Mifta h.pdf.

Mubarak, W.I., Chayatin, N., Rozikin, K \& Supardi. 2007. Promosi Kesehatan Sebuah Pengantar Proses Belajar Mengajar Dalam Pendidikan. Yogyakarta: Graha Ilmu

Notoadmodjo, S. 2012. Promosi Kesehatan dan Perilaku Kesehatan. Jakarta: Renika Cipta.

Nugraheni, N. D., Basuki, W. S., Candrasari, A., Hernawan, B. 2021. Hubungan Kebiasaan Meroko dan Mengkonsumsi Kafein Dengan Kejadian Osteoporosis pada Usia Lanjut. Jurnal Ilmiah Mahasiswa Kedokteran Indonesia Volume 9.1 Edisi Maret - Juli. Diakses melalui https://bapin-ismki.ejournal.id/jimki/article/view/368

Nurmala, I., Rahman, F., Nugroho, A., Erlyani, N., Laily, N., Anhar, Y. V. 2018. Promosi Kesehatan. Surabaya: Airlangga University Press.

Nursalam. 2016. Metodologi penelitian Ilmu Keperawatan. Jakarta: Salemba Medika

Pakpahan M, Siregar D, Susilawaty A, Mustar Tasnim, Ramdany R, Manurur I. E, Sianturi E, Marianna, Sitanggang F. Y, dan Maisyarah M. 2021. Promosi Kesehatan dan Perilaku Kesehatan. Penerbit : Yayasan Kita Menulis. Diakses melalui https://www.google.co.id/books/e dition/Promosi_Kesehatan_dan Perilaku_Kesehatan

ISSN 2502-1524
Pusat Data dan Informasi Kementerian Kesehatan. 2020. Situasi osteoporosis di Indonesia. Diakses melalui https://pusdatin.kemkes.go.id/res ources/download/pusdatin/infoda tin/Infodatin-Osteoporosis2020.pdf

Riyanto A, dan Budiman. 2013. Kapita Selekta Kuesioner Pengetahuan dan Sikap dalam Penelitian. Jakarta: Salemba Medika.

Rizkia, F. A.P. 2012. Hubungan tingkat pengetahuan osteoporosis dengan perilaku pencegahan osteoporosis pada wanita pre menopause. Diakses melalui https://digilib.uns.ac.id/dokumen/ detail/29261

Siregar, A.P., Harahap, A. R., Aidah, Z. 2020. Promosi kesehatan lanjutan dalam teori dan aplikasi Edisi Pertama. Jakarta : Penerbit Kencana. Diakses melalui https://www.google.co.id/books

Sulistyawati, dan Atikah. 2010. Menopause dan Sindrome Premenopause. Yogyakarta: Nuha Medika

Utami, M. H. Fauziah, A. D., Yurezka, B., Pratiwi, Y. A., Dilla, I. H., Putri, T. R., Winaputri, N., Pertiwi, V., Arum, R. A., Chrisna, B. 2015. Review penyakit non menular osteoporosis. Diakses melalui https://scholar.google.com/schola r

Wardhana., Wisnu., Nugroho, Hapsari., Rebriarina. 2012. Faktor-Faktor Risiko Osteoporosis Pada pasien Usia diatas 50 Tahun. Diakses melalui

http://eprints.undip.ac.id/37820/ 
Wildawati, R., Anggreny, Y., Putri, K Dewi. 2020. Determinan pencegahan osteoporosis pada wanita menopause. Jurnal Ners Indonesia, Vol. 10. No. 2 Maret 2020. Diakses melalui https://jni.ejournal.unri.ac.id/inde x.php/JNI/article/view/7979/pdf

Wirakusuma, 2007. Mencegah Osteoporosis Lengkap dengan 39 Jus \& 38 resep makan. Cetakan I. Jakarta : Penebar Swadaya 